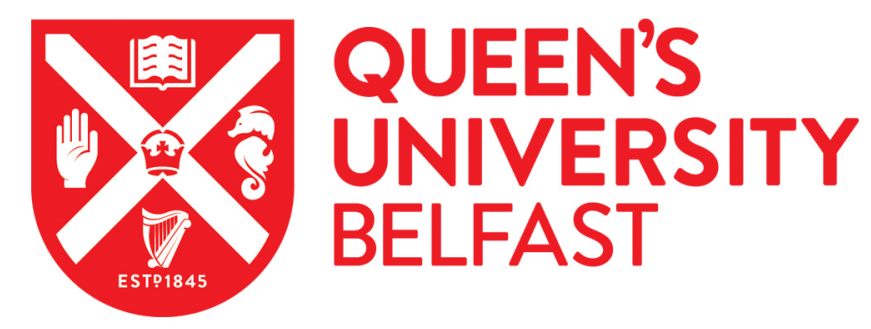

\title{
Young Women's Positive and Negative Perceptions of Self in Northern Ireland
}

McAlister, S., \& Neill, G. (2007). Young Women's Positive and Negative Perceptions of Self in Northern Ireland. Child Care in Practice, 13 (2)(3), 167-184. https://doi.org/10.1080/13575270701353416

Published in:

Child Care in Practice

Queen's University Belfast - Research Portal:

Link to publication record in Queen's University Belfast Research Portal

\section{General rights}

Copyright for the publications made accessible via the Queen's University Belfast Research Portal is retained by the author(s) and / or other copyright owners and it is a condition of accessing these publications that users recognise and abide by the legal requirements associated with these rights.

Take down policy

The Research Portal is Queen's institutional repository that provides access to Queen's research output. Every effort has been made to ensure that content in the Research Portal does not infringe any person's rights, or applicable UK laws. If you discover content in the Research Portal that you believe breaches copyright or violates any law, please contact openaccess@qub.ac.uk. 
This article was downloaded by:[Queens University Medical Library]

On: 11 June 2007

[Queens University Medical Library]

Access Details: [subscription number 769788114]

Publisher: Routledge

Informa Ltd Registered in England and Wales Registered Number: 1072954

Registered office: Mortimer House, 37-41 Mortimer Street, London W1T 3JH, UK

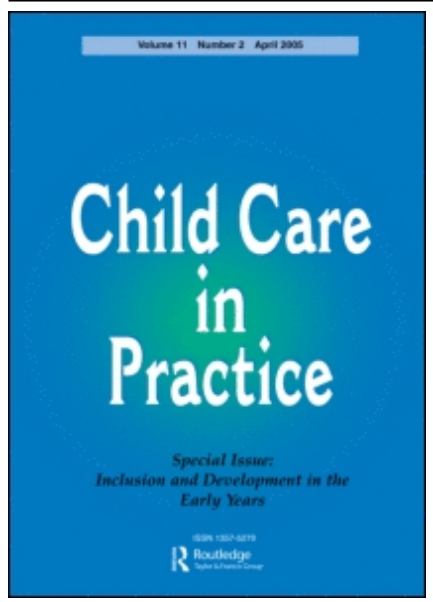

\section{Child Care in Practice}

Publication details, including instructions for authors and subscription information: http://www.informaworld.com/smpp/title content=t713410012

Young Women's Positive and Negative Perceptions of Self in Northern Ireland

To cite this Article: McAlister, Siobhán and Neill, Gail , 'Young Women's Positive and Negative Perceptions of Self in Northern Ireland', Child Care in Practice, 13:3, 167 184

To link to this article: DOI: $10.1080 / 13575270701353416$

URL: http://dx.doi.org/10.1080/13575270701353416

Full terms and conditions of use: http://www.informaworld.com/terms-and-conditions-of-access.pdf

This article maybe used for research, teaching and private study purposes. Any substantial or systematic reproduction, re-distribution, re-selling, loan or sub-licensing, systematic supply or distribution in any form to anyone is expressly forbidden.

The publisher does not give any warranty express or implied or make any representation that the contents will be complete or accurate or up to date. The accuracy of any instructions, formulae and drug doses should be independently verified with primary sources. The publisher shall not be liable for any loss, actions, claims, proceedings, demand or costs or damages whatsoever or howsoever caused arising directly or indirectly in connection with or arising out of the use of this material.

(C) Taylor and Francis 2007 


\section{Young Women's Positive and Negative Perceptions of Self in Northern Ireland} Siobhán McAlister \& Gail Neill

This paper represents analysis of one aspect of a larger research project examining the everyday lives and experiences of young women in Northern Ireland. As an introductory exercise within focus groups, 48 young women considered and discussed the good and not so good things about being a young woman in Northern Ireland. Through these accounts many issues emerged, some in direct contrast and contradiction to one another.

The area focused upon for the purpose of this paper is the body, particularly with regard to body image (self-expression versus pressure) and becoming a woman (growing up versus menarche). The aim is to illustrate that what young women cite as being potentially positive aspects of growing up or being a young woman often have negative experiences and implications attached to them. In light of the advancements made by young women in Northern Irish society, an opening of opportunities and their awareness of the persistence of gendered messages regarding their bodies, many young women are of the belief that such messages have less impact upon them today and that gender is a barrier that can be overcome. It is illustrated and argued here, however, that dominant cultural messages regarding women's bodies are more subtle, confusing and perhaps pervasive than they ever have been. As a consequence, this has created more pressure and confusion for young women and tensions exist in terms of young women's beliefs and their actions. In light of these research findings, this paper considers practice implications for those working with and for young women.

\footnotetext{
Dr Siobhán McAlister is a Research Fellow in the Institute of Criminology and Criminal Justice, Queen's University, Belfast. Ms Gail Neill is a Research and Programme Co-ordinator within the Gender Equality Unit of YouthAction Northern Ireland. Correspondence to: Ms Gail Neill, YouthAction Northern Ireland, 14 College Square North, Belfast BT16AR, UK. Email: gail@youthaction.org. This research was carried out by YouthAction Northern Ireland in partnership with the University of Ulster and was funded by the Big Lottery Fund. Further members of the research team contributed in various ways to the research process, including Dr Ann-Marie Gray (UUJ), Eliz McArdle (YouthAction: NI) and Kate Moore (Peer Researcher). The authors would like to thank all of the young women who took the time to be involved in the research and the anonymous reviewers for insightful comments on the first draft of this paper.
} 


\section{Introduction: The Position of Women in Northern Ireland}

In light of socio-economic and global changes over the past 30-40 years we have witnessed many changes to education and labour markets and to social policies that have had a direct impact on young people. As a consequence, the transition from youth to adulthood has become much more complicated and uncertain for young people today in terms of the steps they would have traditionally made to symbols of adulthood such as employment, independence and parenthood (Furlong \& Cartmel, 1997; Jones, 2002; MacDonald \& Marsh, 2005; McAlister, 2007). While all young people face a new set of risks, they are also faced with new opportunities; and some argue that, within this context, youth transitions have become individualised and cut free from the social origins of young people. By this they mean that traditional social divisions such as gender, class, "race", ethnicity, and so forth, are much less influential in the lives, experiences and outcomes of young people today (Beck, 1992).

In many respects, it would appear that women are faring particularly well under this "new" set of social arrangements. In Northern Ireland in 2004/05 for instance, $71 \%$ of girls compared with $55 \%$ of boys achieved at least five $\mathrm{A}^{*}-\mathrm{C}$ grades at GCSE and $53 \%$ of girls left school with two or more A-levels, compared with $36 \%$ of boys. Furthermore, $60 \%$ of all students enrolled in Northern Ireland universities were women, and women in Northern Ireland are experiencing historically high levels of employment (Department of Enterprise, Trade and Investment Northern Ireland, 2006). It would appear that, on the face of it, gender inequalities (particularly with regard to education and employment) have all but disappeared, young women are faring better than they ever have done, they have more opportunities and choices available to them, and gender divisions, expectations and assumptions are less influential. Behind these statistics, soundbites and success stories, however, is the lived experience of young women, and the data from this research would suggest that, despite the views of some - young women included - gender still very much matters today.

While the advancements made by women should not be forgotten, it is argued here that an almost exclusive focus on these and the increased options available to young women has led young women themselves to believe that they can be whoever they want and attain whatever they want-as long as they take advantage of the opportunities afforded to them. In this respect, many of the young women involved in this research failed to recognise the structural inequalities within their own lives, the bounded nature of agency they worked within (Evans, 2002) and the persistence of gender inequalities. Indeed, this paper argues that traditional gendered messages and expectations persist but often in much more subtle and confusing ways than in the past. In the words of one young woman:

... there's so much media and so much literature about the fight for the woman going back hundreds of years and look how far it's come, then has it really? ...// ... it's quite confusing when you're led to believe that you can do anything, but 
then when you try, you get knocked down and you think to yourself "what's it all about?"

Moving away from the traditional focus on education and employment, this paper highlights other ways in which gendered messages and ideologies persist (i.e. in relation to women and their bodies), and discusses the continued impact of this upon the lives of young women. This focus is taken as it was a key issue to emerge throughout focus group discussions with young women and it revealed some of the contradictory and confusing messages they are receiving and trying to interpret. Through an analysis of this focus group data it is argued that dominant patriarchal ideologies persist, but are concealed in visions, messages and text concerning the empowerment of women, the celebration of womanhood, choice, individuality, freedom and a breaking from age-old gender inequalities and assumptions. How young women make sense of these messages and the contradictory nature of them is considered, as are the implications of this for those working with and for young women in a Youth Work capacity and beyond.

\section{Background to the Research}

The findings presented here represent one aspect of data collected as part of a threeyear feminist action research project (McAlister et al., 2007). The research builds upon and updates a piece of research undertaken by the Gender Equality Unit of YouthAction Northern Ireland over 15 years ago, which examined statutory youth work provision for young women across Northern Ireland (Trimble, 1990). Many of the target groups with which the Unit now works and the nature of the programmes run with them were a direct response to the recommendations highlighted in that report. It is expected, therefore, that the research discussed here will likewise redirect the Unit's work as well as influence policy and practice on a larger scale.

While there are a number of stages and dimensions to the research, one of the first aims was to set up a Young Women's Working Group - a group of young women from diverse backgrounds throughout Northern Ireland who would inform the research at all stages. In consultation with them, the second stage was to consider what information to collect from young women in the form of focus group interviews and the appropriate means of running these. This was to represent the first stage of data collection and entailed running seven focus groups with 48 young women. While producing data in their own right, the wider aim of these was to identify issues of importance to young women themselves in order that they could be explored in more detail in the third stage of the research - in-depth qualitative interviews $(n=43)$. Preliminary analysis of research findings were taken to the Young Women's Working Group, who decided which issues to focus upon for designing resources and programmes of work in order to inform other young women and those working with them. Four resources have been designed by these young women and these resources, along with others, have and will continue to form the basis of programmes of work with young women throughout Northern Ireland. 


\section{A Feminist Approach}

As young women were the focus of the research and it was about their lives, their views and their experiences, the aim was to ensure that they were at the heart of the research from start to finish. It is for this reason that a feminist approach was adopted. Not only does feminist research take women as its starting point in so far as it recognises women's stories as legitimate sources of knowledge, the way in which these stories are collected, analysed and disseminated is done with an ethic of "respect, collaboration and caring" (Campbell \& Wasco, 2000, p.775).

While there is no singular feminist methodology, five principles that guide feminist research have been identified (see Brayton, 1997, pp. 9-10). Firstly, women and gender are the focus of analysis; secondly, it is about consciousness-raising at an individual level for both the participant and the researcher. Thirdly, there is a rejection of the power imbalances between the "researcher" and the "researched", and a recognition that the researcher is an inherent part of the research process. Fourthly, there is a concern for ethics in terms of responsibilities to individual participants and the wider use of research findings. And finally, it is about the empowerment of women and changing gender inequalities in society as a whole. The research team sought to implement these principles in all aspects of the research process, and the setting-up of the Young Women's Working Group is a clear example of one of the principles of feminist action research in practice (i.e. the empowerment of women through the research process).

\section{Focus Group Discussions}

While the research team and the Young Women's Working Group had identified some themes to be explored in focus groups, the aim was that the young women involved in these would come up with their own issues and concerns. Before moving into a themed or focused discussion, therefore, a short group exercise that acted as a form of "stimulus material" was compiled and carried out (Kitzinger \& Barbour, 1999). This entailed each member of the group considering the good and not so good things about being a young woman and the good and not so good things about being a young man. Each member of the group recorded their thoughts on a sheet provided and reported points back to the full group. The fact that the young women had written points down and reported them back displayed a willingness to talk about these in a group context.

It has been noted that the group context also provides a supportive environment to discuss views and experiences, particularly when there is commonality and similarity of experience. There were, for example, issues raised and discussed in this group context which rarely came up in the one-to-one interviews. The sharing of experience, therefore, can be empowering and consciousness-raising in that it allows young women to talk about issues that might otherwise be taboo and to see that they may not be alone in their views and experiences (Wilkinson, 1998). 
Seven focus groups were run in various locations throughout Northern Ireland. These comprised of a total of 48 young women aged between 13 and 25 years, and the mean age of the sample was 17 years. The aim was to talk with young women from diverse backgrounds and locations, and those groups identified for inclusion included:

- Young women living in rural areas (one predominantly Catholic, one predominantly Protestant).

- Young women living in urban Belfast (predominantly Protestant).

- Young women living in an interface area outside Belfast (predominantly Catholic).

- Young women attending a grammar school (mixed religion).

- Young women from minority ethnic communities.

- Young women living in Derry/Londonderry (mixed religion).

Focus group discussions lasted between an hour and an hour-and-a-half and, with the permission of all participants, were tape-recorded for purposes of accuracy. While some background information was collected from participants in relation to community background, education/employment status, sexual orientation and motherhood, small numbers within some of these subgroups make it difficult to comment on possible group differences. What is presented here, therefore, are common themes to emerge from all of the young women's discussions. More specifically, this paper focuses on the issues to emerge from the gender exercise carried out as part of these focus groups whereby young women considered the good and not so good things about being a young woman. While all groups identified far fewer positive than negative aspects of being a young woman, those positives they did identify often had a negative attached to them that could overshadow the potential value of the previously identified positive aspects of being a young woman.

\section{Beauty and Fashion: Choices and Constraints}

Clothing, hair and beauty were considered by all groups to be positive aspects of being a young woman. The themes of choice, individuality, self-expression and selfesteem were key to these discussions, alongside the social aspects of related activities such as shopping and getting ready for a night out. The following discussion among one group is reflective of others:

YW1: Most girls have their own way of making themselves feel good and some women feel that make-up and you know, new clothes is sort of this thing that helps us.

YW2: You know, a pick me up.

SM: How does it help you, what does it make you feel?

YW2: Nicer [laughs].

YW3: Yeah makes you feel nicer and better [giggles].

Conversely, young women also noted body image, fashion and beauty as some of the negative aspects of being a young woman, because even though they brought 
the potential for self-expression, this was often within the confines of pre-defined trends and images. Thus, while they felt there was more choice for young women in terms of how they could present themselves and how they could act, it was essentially a greater degree of choice within the traditional confines of a constructed idea of "feminine perfection". As one group of young women noted, the dominant cultural discourse was still one whereby:

YW1: Everyone is expected to look the same, like a Barbie doll.

YW2: Yeah.

YW3: Perfect make-up, perfect hair, perfect figure.

The risks for young women who did not reach or aspire to this perfection, or who were different, were clear:

You have to look pretty and if you don't look like everyone, even the girls, they are gonna think "Oh my God look at her, she's so ugly".

The power of the media and particularly women's magazines in the reproduction of existing social arrangements, patriarchal definitions of the social world and women's subjective understandings of self and what it means to be a woman have been of interest to feminist scholars for many years (Currie, 1997). One criticism of such research, however, has been that women have sometimes been constructed as passive recipients of such messages and thus portrayed as "cultural dupes" (Davis, 1995 cited in Rubin, Nemeroff, \& Russo, 2004, p. 98). This research revealed, however, that young women do have some level of awareness of the objectification of women's bodies and do not "passively accept the images presented" to them (Currie, 1997, p. 35). The young women involved in this research were not ignorant of the fact that the media stereotypes them, sets forward a way of being/looking and that this way of being and looking is often highly unrealistic. Many young women were aware of it and discouraged their friends and admonished themselves to steer away from these restrictive, unrealistic and clone-like roles, yet a tension exists. Posited alongside this knowledge are their experiences. Thus, even in the accounts of those who maintained that they were aware of cultural ideologies surrounding women's bodies and the potential negative impact of this upon young women in terms of self-esteem and body dissatisfaction, there were contradictions between beliefs and actions. While many young women were clear that others may be affected by these messages, they maintained that they certainly were not:

Most girls do it [get dressed up] for others, I wouldn't do it for others, I would do it for myself to make me feel more confident you know sorta to get so I feel confident in myself fitting in a wee bit but not for anybody else.

Despite assertions to the contrary, these young women were body conscious and clearly linked feeling good about themselves (in terms of fitting in and being confident) to the way they looked. This may suggest some level of internalisation of 
cultural messages regarding how women should look and how they are looked at. As Fredickson and Roberts (1997, cited in Rubin et al., 2004, p. 31) note:

The cultural milieu of objectification functions to socialize girls and women to, at some level, treat themselves as objects to be looked at and evaluated.

Further to this, and similar to the findings of other research, although young women were aware that the women presented to them in popular culture were not the norm and were unnaturally beautiful, they still "engaged in a manner of reading that brought their construction of self, rather than ...the discourse, into question" (Currie, 1997, p. 471). In other words, they often compared themselves with media images and depictions of women and questioned themselves more than they questioned the ideology:

YW1: I sat and cried a couple a weeks ago when I was watching the girls on TV [giggles], I just cried for ages [giggles].

SM: Why?

YW1: Because they're all nice [giggles].

Likewise, they admitted to regularly engaging in what Lisa Rubin and her colleagues (Rubin et al., 2004, p. 31) describe as processes of social comparison, whereby "women objectify themselves through gazing at other women". In many cases this was their peers or their classmates but could equally be any woman within any context, and it was through this process of social comparison that many located and explained "bitchiness" among young women. One group of young women, for example, recognised that their treatment of other young women stemmed from jealousy surrounding their physical appearance and subsequently related this to the depiction of women in magazines:

YW1: When someone walks past you, you're like "[tuts] tramp" like that or "stuck up bitch" or whatever.

YW2: I do that if I was jealous of them, "wee bitch" [laughs].

[Group laughter]

SM: Why do you think that does go on?

YW1: If I was jealous [of] somebody, I would usually say, not in a really bad way, but I'd just go "bitch" [giggles], not to her like. I do it when I look in magazines, "oh look at her isn't she lovely? Bitch!" [Giggles]

[Group giggles]

Another group of young women identified bitchiness as stemming from similar sources of competition between women:

YW1: Like pressures ...//... they want to be like everybody else ...//. . they want to be like the nice girls who's got the boys chasing after them, and the ones getting the nice cars, just people that would be like a bit jealous of other people bein' better off than they would be, or have better looks, nicer hair, more money

YW2: Bitchiness is a big thing nowadays I think 
These discussion of "bitchiness" among young women are in some ways similar to notions of "in" and "out" groups in Social Psychology whereby the identity and selfesteem of some (the "in group") is enhanced through prejudice and stigmatisation of others (the "out group") (Vivian \& Brown, 1995). Many young women in this research pointed to the negative part that "bitchiness" played in their own and others' lives. Although earlier viewing their friendships and open expression of emotions as one of the most positive aspects of being a young woman, here they very clearly saw the negative side of this and were aware of the potentially damaging nature of their interpersonal relations with other young women. Constant pressure from the media and youth culture regarding women and what a successful woman is and should look like can place great demands upon young women, especially when they are faced with few opportunities to meet this "ideal". It could be argued, then, that this competition among young women is a manifestation of a patriarchal system whereby women are the object of the male gaze and male desire. Being the object of such desire instils a form of self-worth and confidence, and this system by its very nature encourages "bitchiness" and competition among young women as they vie for a position within it.

In addition to the more typical messages within the media regarding women's bodies, a number of young women also pointed to the confusing and contradictory messages given to young women today. Indeed, they noted that these not only came through the media but also through school and other social institutions. With regards to the confusion around image, one group of young women spoke of the difficulty in working out what exactly was expected of women and thus, of how to present themselves:

YW1: I think image as well [other YW agree], like magazines, there's so much pressure to be aw a size 10 or whatever and like have huge boobs and stuff like that and just be perfect and giggle and toss your hair and that.

YW2: It's weird, you wanna be feminine and you wanna be attractive but you don't want to be seen as that be your only quality.

YW1: Sometimes it can be ...//... a really hard balance to strike

YW3: It is, it is quite [short pause] muddled up this whole thing [everyone laughs].

Again this confusion in part relates to their knowledge of the objectification of women, the tensions between wanting to attain some form of "feminine perfection" because the risks of not doing so can be high, and their recognition that this should not necessarily be the case. In the role models of success and female empowerment that they are presented with, beauty, wealth and success often go hand in hand. Indeed, as McRobbie (2000, p. 200) states:

Flicking through the lifestyle and feature sections of the daily newspapers in the UK and looking more closely at the new world of girls' and women's magazines, it would be easy to imagine that women are no longer in any way hindered by gender, or at least that no obstacle can be overcome. 
Living within a culture that "objectifies female bodies and links women's economic and social power to appearance" (Rubin et al., 2004, p. 28), beauty can be bought or negotiated, fame is open to all irrespective of gender or class (e.g. Big Brother's Jade and Chantelle), as is success, which can be attained through the widening of opportunities to all within education and labour markets. Indeed, the young women in this research identified the increasing avenues open to all to be a "size 10 with huge boobs" and to "fit in a wee bit". This included the likes of plastic surgery, information on fitness and dieting, a greater choice of clothes and fashion, knowing what was fashionable and how their hair and make-up should be done. "Perfection" and the "ideal", therefore, can be achieved or bought through consumerism (Russell \& Tyler, 2005). Status and fame are much more instantaneous, immediate and attainable by all today (Neimark, 1995), and while the focus on celebrities lives within women and girls' magazines may in some respects show that they are human just like us, it "limits our vision to the foibles and failings of those particular individuals" (ibid., p. 84). In doing so, the focus is upon that individual and her "failings", not the wider cultural messages regarding gender that relate to all women.

While a number of groups identified confusions and tensions in the messages given to young women, particularly through the media, only one could clearly articulate the nature and source of the mixed messages they were receiving. The message they identified was one that told them that they could attain what they wanted and be who they wanted, yet they had to do so within the confines of pre-defined traditional gender stereotypes. Of magazines and the confusing messages they give, one young woman summed it up as follows:

... I think it might be in Cosmopolitan or whatever are trying to be all like "yeah women can do this too ...//... be your own person, but here's what you can look like by doing this", you know it's very much all about believing in yourself, be who you want to be, be comfortable in your own skin, but then we can't because we're sent images every two seconds when they advertise something ...//... it's like you have to behave and act a certain way or look a certain way so I think there are some contradictions there.

The message described here is one of freedom, choice, power and individualism - yet within clear constraints - and the dominance of these messages means that larger structures of inequality and the reproduction of gendered messages are less obvious. While there is some recognition among young women of these inequalities and stereotypes, the message as McRobbie points out is that they can be overcome. This view was clearly internalised by one young woman who stated:

These days anyway, I could argue the point about ten years that "I have to be like that", I think you're a wee bit daft now, if you still think that I have to sit there and be quiet. (Her emphasis)

It has been shown here, however, that beliefs and actions were often in conflict and, despite this young woman's beliefs, she too noted the ways in which she engaged in social comparison. She, and others, however, did to an extent blame those young 
women themselves who had been "duped" or "sucked in" by the messages within the popular media regarding the way women should look and be, but, in their minds, this was true of other young women and not them. Despite some level of awareness of wider structural inequalities and cultural messages regarding women, many felt that today young women had the means to overcome these if they took advantage of these means. This is perhaps evidence of what MacDonald and Marsh (2005, p. 33) describe when they state that "the sense of individual autonomy engendered ... obscures the fact that existing social divisions are only reproduced in different ways".

\section{Key Messages and Implications for Practice}

In summing up the previous discussion, Table 1 highlights some of the conflicts and contradictions in young women's lives regarding fashion, beauty and the body. The left-hand column illustrates the messages received by young women while the righthand column illustrates the underlying messages and reality of their experiences.

The clear message is that the objectification of women's bodies is not something of the past, something that has already been dealt with by feminism and by programmes of work with young women. The fact that young women may have some awareness of the mechanisms of the objectification of women's bodies does not mean that they are critically self-aware and unaffected. If anything, today the messages are more subtle, confusing and pervasive.

The group setting provides a forum for young women to share and talk about issues around the objectification of women's bodies, the contradictions and confusion they experience. The sharing of such experience can empower young women by helping them see that they are not alone in their feelings and experiences. Thus, future programmes of work with young women should continue to contain an element of work on body objectification. Alongside this, there are a number of other issues that can be considered in such work with young women and at a more general level. These might include the consideration of:

- Other ways to encourage self-worth in young women, such as through the development of new skills, strong social networks and personal achievement.

Table 1 Conflicting Messages Regarding Fashion, Beauty and the Body

\begin{tabular}{ll}
\hline At face value & \multicolumn{1}{c}{ Lived experience } \\
\hline Pleasure & Pressure \\
Self-expression & Follow current trends \\
Control/agency & Within constraints/“bounded agency” \\
Be individual/do it for yourself & So long as you are perfect \\
Stand out & Fit in \\
You can be whoever you want & As long as it is like this \\
Be comfortable in your own skin & If it looks like this \\
\hline
\end{tabular}


- How to raise and maintain a critical awareness among young women of what the messages are, how and why they are cultivated-critical awareness is in itself a strategy for resisting cultural messages about women's bodies.

- Providing alternative ways of seeing women's beauty and young women seeing themselves.

- Equipping young women with the skills to recognise the impact body objectification has upon themselves and their relations with other young women.

- Encouraging young women to seek non-objectifying ways of experiencing their bodies and themselves - through placing emphasis on areas such as health, ability, uniqueness, and so on.

- Promoting and raising self-awareness among those working with young women. This entails being aware of the messages we as individuals send to those we work with and ensuring not to reinforce patriarchal messages that we over time may have also come to internalise.

- Making visible, alternative positive images of women's beauty in offices, training rooms and promotional material. (See also Rubin et al., 2004)

\section{Becoming a Woman: The Significance of Menarche}

Several young women noted the transition from girl to woman as a positive aspect of being a young woman. For them this signalled a major change in their lives towards developing a woman's body and shape, being given more freedom, being more "grown up", being taken more seriously and being afforded a more adult status. As one young woman stated:

For me it was about [pause] you know I'm not a wee girl anymore, you know I'm what you call a woman.

In reality, and despite this being something they looked forward to, the true nature and impact of the transition to womanhood was something many found difficult and confusing. With physical change also came emotional change that many women were unprepared for. Freedom was still not granted (due to fears for safety and surrounding unplanned pregnancy), and often rather than being taken more seriously they found that their bodies and emotions were the site of ridicule and personal dissatisfaction.

Aside from general body dissatisfaction, menarche (or the first period) as the physical and emotional symbol of development (Burrows \& Johnson, 2005; Fingerson, 2005) was by far the most frequently cited and intensely discussed negative aspect of being a young woman. There were a number of themes to emerge when discussing menstruation, including: the impact of girls' first periods (menarche) and the fear and embarrassment surrounding this unpreparedness; the lack of knowledge/information some young women had regarding this; the impact of emotional as well as physical change; a frustration about men reducing young 
women's emotions to hormones once they had started to develop; and the restricting impact that periods had on their lifestyles.

In her research on menstruation with adolescent boys and girls, Lovering (1995, p. 10), among others, has noted that "adolescents have largely negative attitudes to, and a lack of knowledge about, menstruation". Similar could be said of some of these young women in their reflections of their first period and attitudes towards menstruation in general. In terms of negative attitudes, some of these were displayed particularly strongly among one group of young women:

SM: What about the not so good things about being a woman?

YW1: Periods.

YW2: [whispers] $\mathrm{F}^{\star \star} \mathrm{k}$ !

[Group laughter]

SM: O.K. So what is it that's so negative about like periods for a woman then?

YW1: Everything

[General consensus]

YW2: Everything about it

...//...

YW1: It's disgusting

This is only one example of the negative views young women held regarding their bodies, describing periods as "disgusting" and "dirty" and their experiences of them in discourses of embarrassment, fear, secrecy and discomfort (see also Burrows \& Johnson, 2005). If we look to some of the newest feminine hygiene products and the advertising of these we can begin to see how some of these young women's views are influenced. Not only is there Tampax Compak, which can be hidden more easily, hence perpetuating ideas that menstruation is something secretive and embarrassing, but there is now Tampax Fresh, which are scented tampons, playing on notions that menstruation is something unclean. As Rebecca Ginsberg notes: "the design of the objects and their packaging can be read as encouraging private discreet consumption" (cited in Al-Khalidi, 2000, p. 65).

Lovering (1995, p. 13) notes the importance of considering "how and where knowledge is produced, and by whom" and points to the "patriarchal nature of menstrual attitudes" (p. 11). It is her contention that the subjective meanings young women attach to their bodies and menstruation (e.g. embarrassment and "shame") are the result of "patriarchal sexual discourses"; that is, ways in which female bodies are subjected to the male gaze. This embarrassment could be seen in a number of the accounts of the young women we spoke to, but the source of it is discussed in part in the following discussion with a younger group (mean age 14 years):

YW1: It is even embarrassin' watchin' advertisements.

[Group laughter]

...//...

YW2: My Ma got me to go into the shop for them and I was never so embarrassed in all my life!

[Everyone laughs]

SM: Should young women be embarrassed about these sorts of things? 
All YW:Naw

YW3: We shouldn't really but we are

SM: Why do we think we are embarrassed?

YW1: Cos people laugh at ye [laughs].

...//...

YW3: Especially round here if you walk into a shop to get them-

YW4: The boys would all make fun of ye.

[YW agreeing in background]

Here the young women explain their various levels of embarrassment showing how male behaviour or gendered power relations are often the source of it. The fact that this particular group of young women lived in a small community with a lack of privacy perhaps intensifies these feelings. It is also interesting to note the use of laughter/humour and non-specific language (e.g. "them" when referring to feminine hygiene products) throughout the discussion. Key features of all discussions around menstruation were "mutual self-disclosure and laughter" (Green, 1998, p. 179), and here laughter appeared to be a technique used when sharing intimate details as a means of deflecting from their seriousness. Interestingly and in relation to this, Green (1998, p. 179) has noted:

women drawing on feminist discourses, for example those which cite socialization rather than biology as the mechanism through which women learn to undervalue themselves, often use a joking style and laughter to acknowledge the discrepancy between feminist ideas and what is commonly accepted as the "real" world.

With regards to the patriarchal nature of menstrual attitudes, there were many examples of these cited in terms of men devaluing the actual menstrual experience and reducing all women's emotions to hormonal change. The following extracts are illustrative of these:

They [men] make fun of it like my Dad who says it's just a big conspiracy for women to get sympathy and sit on their ass all day.

YW1: Wee fellas ...//... all ya get outta them is, see if they say somethin' that you don't agree with and you turn round and tell them to shut up, "her time of the month, leave her alone" [number of young women in background agreeing] and then they turn round and say "aye look at girls they get the excuse, it's their time of the month they can say whatever they want and do whatever they want".

...//...

YW2: We're condemned for it.

YW3: We're put down because of it.

These are clear examples of gender power relations where men exert their dominant position by reducing women's experiences to something meaningless and construct their feelings/emotions as "irrational". The example of using women's biology to devalue a viewpoint because it is different to that of the young man's is a classic 
example of the way in which male power is used to re-produce this dominant patriarchal discourse.

A further example of the fear and embarrassment experienced by young women with regards to menstruation was in relation to their first periods, and it is perhaps through these initial experiences that we begin to see how their attitudes and feelings are formed. With regards to their first periods a number of young women shared vivid memories with us and their peers. The fact that a number remembered the exact date, location and feelings of fear and embarrassment (despite often being in their 20s now), highlights the impact and importance of this time of their lives:

YW1: All the fear and embarrassment telling your Mum cos you don't really know what's going on really, em cos I know I had mine young and I didn't really know what was going on and I was on holidays and I remember the date and everything; it was $29^{\text {th }}$ July

[Group erupts in laughter]

...//...

YW2: Mine was the $24^{\text {th }}$ March, $y^{\prime}$ know what I mean [group laughter]. You just remember your date, like it's so strange like. And I remember like, and my Mum was sitting at the bar, I was out and I go "Mummy I'm bleeding" and then she started to cry. And she came in then and sat me down and told me what it was all about...

What was clear from the discussions among many young women was the lack of knowledge many had prior to starting their first periods and the fear and embarrassment they experienced as a result of this. Like in Kissling's (1996) research with adolescent girls and their mothers, some of these young women spoke of having "a talk" at school and/or from their mothers. In light of the impact of menarche and attitudes to menstruation as discussed here, one-off "talks" would appear insufficient to deal with the variety and intensity of emotions that can come with menarche. This was evidenced by the fact that the small number of young women who felt better prepared and informed (generally by their mothers or sisters) felt less fearful when they experienced their first periods. Conversely, none of the young women we spoke to reported holistic, value-free information provided through their respective schools in relation to menarche and emotional development. This is clearly an area where more work is needed, particularly in light of the fact that some mothers of these young women had never discussed this with their daughters.

In reference to young women's lack of knowledge and feelings of "shame", Lovering (1995, p. 22) suggests that patriarchal sexual discourses have led mothers to often feel discomfort and embarrassment in informing their daughters, seeing this as something of a "private discursive practice, not so much unseen and unspoken as covered up and hushed up". Thus, there is evidence of a "communication taboo" whereby menstruation cannot be openly talked about and must be verbally as well as physically concealed (Kissling, 1996, p. 484). From many sources of knowledge about menstruation (mothers, advertisements, schools), young women learn implicit messages that it is something "different", something unique to females and not talked about (especially in front of men) and hence, something secret and hidden. 
These social rules surrounding menstruation are "intricately linked with feelings of shame and discomfort" (ibid., p. 483). The cultural meanings that this group of young women attach to menstruation as passed on from others, therefore, may be reflective of a Northern Irish society that treats many aspects of sex and sexuality as taboo (for fuller discussion see McAlister et al., 2007). This clearly impacts upon how women are viewed within this society for, as Kissling suggests, "menstruation is ... important as a symbol of femaleness; how society deals with menstruation can reveal a great deal about how that society views women" (1996, p. 482).

What remains clear is that across all ages and backgrounds these young women did, in the main, when younger, lack knowledge about menstruation. Even when it was covered in school, the young women found the information confusing, the fact that they were separated from the boys (who on one occasion looked in the window and laughed) embarrassing and the information patchy. One group in particularly urged that schools teach young women more around "periods and body change" noting the importance of focusing on emotional as well as physical change. The confusion and at times isolation felt during adolescence was felt to be something about which young women were not informed as the focus was always upon the physical. It is well accepted that adolescence is a time when young women's selfesteem, especially relating to the body, is particularly low; negative attitudes towards menstruation, therefore, can further impact upon this.

Patriarchal attitudes towards menstruation have a clear impact upon how young women view this aspect of being a woman as something shameful, embarrassing and "disgusting". The manner in which information is passed on to young women at home, in their schools and through advertising engender the view that this is as aspect of women's bodies that should remain hidden, yet it too is subject to the male gaze. Furthermore, their lack of knowledge regarding emotional as well as physical change at a crucial developmental stage can intensify feelings of a lack of control over their bodies and of confusion and isolation.

\section{Key Messages and Implications for Practice}

In summing up the previous discussion, Table 2 highlights some of the conflicts and contradictions in young women's lives regarding womanhood. The left-hand column illustrates the messages received by young women while the right-hand column illustrates the underlying messages and reality of their experiences.

Table 2 Conflicting Messages on Womanhood

\begin{tabular}{ll}
\hline At face value & \multicolumn{1}{c}{ Lived experience } \\
\hline Celebrate womanhood & Keep most physical signs of it taboo \\
Growing up & Continued restrictions \\
Private & But subject to the male gaze \\
Physical change & Emotional change
\end{tabular}


Many young women remain unprepared for menarche and are, therefore, often powerless over this aspect of their lives. The reality can be disappointing and bewildering. In light of this and related findings there are a number of issues that those working with young women could give further consideration to. These include:

- An understanding that knowledge is the key component in empowering young women. Opportunities for sharing information surrounding periods and body change with young women should, therefore, be maximised.

- Recognition that traditional means of educating young women concerning periods and other issues related to puberty and womanhood may need review in order to ensure that these lessons are communicated in a way that is understood by young women and that focuses not purely on physical changes but the emotional as well.

- Remembering that the way in which adults talk about their bodies and menstruation impacts upon young women. It is vital that positive role-modelling be witnessed.

- In programming that focuses on the body, information about menstruation should be built in to allow young women to talk about their attitudes and experiences in a group setting, to consider where the messages about "dirty", "disgusting", "embarrassing" come from (use adverts, etc.) and to combat these messages through creative group work programmes and discussions.

- In programme planning and delivery ensuring that, when possible, the positive elements regarding menstruation are also highlighted.

\section{Conclusion}

Set alongside the glowing soundbites and statistics about the position of women in society today, the increased opportunities and options available to them and the message that they can be whoever they want and comfortable in their own bodies, is the reality of their lives. Subjects studied, careers education, training and employment routes in Northern Ireland remain divided upon traditional gender lines, and women's bodies remain the object of the male gaze. As young women grow up in a society that encourages individualism and competition, they face many pressures, conflicts and confusions. Many firmly believe that they can achieve and that hurdles can be overcome. While not devaluing this ethos and the empowering impact it may have, many of the young women we spoke to were failing to fully recognise that the difficulties and confusions they faced were not individual, but part of larger structural and cultural processes. This belief among young women poses particular difficulties for those working with and for them. Many of the young women involved in this research recognised the gains of feminism in the past but felt that it was fairly outdated in the current climate of increased equality. Inequalities today, however, are more concealed than in the past, and while the young women were aware of gender stereotyping, they felt that it impacted minimally upon their lives as they, unlike their mothers and grandmothers, had the opportunities to move beyond and challenge these. Despite having noted some considerations for work with young women, in 
light of their beliefs there are additional challenges and concerns for those working with and for them; notably, how do we engage young women in gender conscious work and young women's groups when they may see little need for them? Do we risk disempowering young women by enabling them to reassess continued inequalities and the persistence of gendered messages in their families, schools, leisure sites, employment experiences and the media? While we believe that this is in fact a process of empowerment rather than disempowerment, these are serious questions that the youth service and those working directly with young women must begin to consider.

There are clearly some limitations with the research discussed here that could be enhanced through further research on young women and the body. What we have reported here are the general attitudes and experiences of young women as a whole and we are aware that there may well be group differences (e.g. by age, socioeconomic status, those who are mothers, etc.). Furthermore, while focus group discussions are a good means of gathering information on subject areas where a group has a shared understanding and commonality of experience, they are not always the best forum for delving into personal and potentially sensitive issues (e.g. individual responses to the desire to reach "body perfection"). That said, given recent media discussions of "Yummy Mummy's", "Zero sized models" and "teenage obesity", this research provides a glimpse into the potential impact of these and related discussions on young women's perceptions of themselves, their relations with other young women and the continued objectification of women's bodies in today's society. The popularity of these discussions at present also provides the perfect opportunity to carry out work with young women in exploring where these messages come from and the meaning of them for their lives.

\section{References}

Al-Khalidi, A. (2000). "The greatest invention of the century": Menstruation in visual and material culture. In M. Andrews \& M. Talbot (Eds.), All the world and her husband: women in twentieth century consumer culture. London: Cassell.

Beck, U. (1992). Risk society: Towards a new modernity. London: Sage.

Brayton, J. (1997). What makes feminist research feminist? The structure of feminist research within the social sciences. Source unknown.

Burrows, A., \& Johnson, S. (2005). Girls' experiences of menarche and menstruation. Journal of Reproduction and Infant Psychology, 23(3), 235-249.

Campbell, R., \& Wasco, S. (2000). Feminist approaches to social science: Epistemological and methodological tenets. American Journal of Community Psychology, 28(6), 773-791.

Currie, D. (1997). Decoding femininity: Advertisements and their teenage readers. Gender \& Society, $11(4), 453-477$.

Department of Enterprise, Trade and Investment Northern Ireland (2006). Women in Northern Ireland: September 2006. Retrieved 3 February, 2007, from http://www.detini.gov.uk/cgi-bin/ downdoc?id $=2466$

Evans, K. (2002). Taking control of their lives? Agency in young adult transitions in England and the new Germany. Journal of Youth Studies, 5(3), 245-270.

Fingerson, L. (2005). Agency and the body in menstrual talk. Childhood, 12(1), 91-110.

Furlong, A., \& Cartmel, F. (1997). Young people and social change: Individualization and risk in late modernity. Buckingham: Open University Press. 
Green, E. (1998). "Women doing friendship": An analysis of women's leisure as site of identity construction, empowerment and resistance. Leisure Studies, 17, 171-185.

Jones, G. (2002). The youth divide. York: Joseph Rowntree Foundation/York Publishing Services.

Kissling, E. (1996). Bleeding out loud: Communication about menstruation. Feminism and Psychology, 6(4), 481-504.

Kitzinger, J., \& Barbour, R. (1999). Introduction: The challenge and promise of focus groups. In R. Barbour \& J. Kitzinger (Eds.), Developing focus group research: Politics, theory and practice. London: Sage.

MacDonald, R., \& Marsh, J. (2005). Disconnected youth? Growing up in Britain's poor neighbourhoods. Houndsmill: Palgrave.

McAlister, S. (2007). An ethnographic investigation of "underclass youth": a case study of Blossom Hill: Teesside. Unpublished Ph.D. thesis, University of Teesside, UK.

McAlister, S., Gray, A., \& Neill, G. (2007). Still Waiting: The stories behind the statistics of young women growing up in Northern Ireland. Belfast: YouthAction Northern Ireland.

Lovering, K. (1995). The bleeding body: Adolescents talk about menstruation. In S. Wilkinson \& C. Kitzinger (Eds.), Feminism and discourse: Psychological perspectives. London: Sage.

McRobbie, A. (2000). Feminism and youth culture (2nd ed.). Houndsmills: Macmillan Press Ltd.

Neimark, J. (1995). The culture of celebrity. Psychology Today, 28(3), 54.

Rubin, L., Nemeroff, C., \& Russo, N. (2004). Exploring feminist women's body consciousness. Psychology of Women Quarterly, 28, 27-37.

Russell, R., \& Tyler, M. (2005). Branding and bricolage: Gender, consumption and transition. Childhood, 12(2), 221-237.

Trimble, J. (1990). Equality of opportunity?: Provision for girls and young women in the full time sector of Northern Ireland Youth Service. Belfast: YouthAction Northern Ireland.

Vivian, J., \& Brown, R. (1995). Prejudice and intergroup conflict. In M. Argyle \& A. Colman (Eds.), Social psychology. London: Longman.

Wilkinson, S. (1998). Focus groups in feminist research: power, interaction, and the coconstruction of meaning. Women's Studies International Forum, 21(1), 111-125. 